\title{
Higher protein intake increases cardiac function parameters in healthy children: metabolic programming by infant nutrition-secondary analysis from a clinical trial
}

\author{
Rosa Collell', Ricardo Closa-Monasterolo ${ }^{2,3}$, Natalia Ferré ${ }^{3}$, Veronica Luque, ${ }^{2,3}$, Berthold Koletzko ${ }^{4}$, Veit Grote ${ }^{4}$, Roman Janas ${ }^{5}$, \\ Elvira Verduci ${ }^{6}$ and Joaquín Escribano ${ }^{1,3}$; for the European Childhood Obesity Project Group.
}

BACKGROUND: Protein intake may modulate cardiac structure and function in pathological conditions, but there is a lack of knowledge on potential effects in healthy infants.

METHODS: Secondary analysis of an ongoing randomized clinical trial comparing two groups of infants receiving a higher (HP) or lower (LP) protein content formula in the first year of life, and compared with an observational group of breastfed (BF) infants. Growth and dietary intake were assessed periodically from birth to $2 \mathrm{y}$. Insulin-like growth factor 1 (IGF-1) axis parameters were analyzed at 6 mo in a blood sample. At 2 y, cardiac mass and function were assessed by echocardiography.

RESULTS: HP infants $(n=50)$ showed a higher BMI $z$-score at 2 y compared with LP $(n=47)$ or BF $(n=44)$. Cardiac function parameters were increased in the HP group compared with the LP and were directly related to the protein intake during the first 6 mo of life. Moreover, there was an increase in free IGF-1 in the HP group at 6 mo.

CONCLUSION: A moderate increase in protein supply during the first year of life is associated with higher cardiac function parameters at 2 y. IGF- 1 axis modifications may, at least in part, underlie these effects.

$\mathbf{T}$ here is compelling evidence that the type of nutritional exposure in early periods of an organism's development may affect the structure and function of body tissues later in life $(1,2)$. Protein intake may play a key role in modulating body mass and function of various organs and systems $(3,4)$. This influence can be exerted by a direct effect on the target organs (5) and via the modulation of whole body size (6) resulting in functional load of vital organs. Recent evidence indicates that feeding infant formulas with higher protein (HP) content resulted in an increased kidney volume, with a direct effect on kidney function, and an increase in whole body mass $(3,7)$. One of the target organs affected by early protein intakes is the heart, the development of which occurs in an early embryonic phase. As such, early postnatal nutrition would affect growth since this is the period in which the fastest growth of the body and organs takes place. Effects of protein supply in pregnancy on left ventricular function have been described in rats (8). Similarly, infants and children suffering from protein-energy malnutrition have been shown to have reduced left ventricular mass (LVM) and function (9-11) proportional to body surface (10). In animal models, early life overnutrition has been associated with left ventricular hypertrophy (12). Investigations have been conducted on cardiac function parameters under extreme protein supply situations, but data are lacking on the effect of normal protein supplies on these parameters.

Proteins serve as structural substrates for heart tissue development. However, proteins can also affect the growth of the heart through a systemic stimulation of the constituents of the insulin-like growth factor 1 (IGF-1) axis. The rationale in suggesting this mechanism is based on the observation that increased protein intakes, via infant formula diets, under nonextreme conditions, stimulate the growth of other organs, such as the kidney (7). Further, cardiac hypertrophy in acromegaly is partly mediated by the growth hormone (GH)/IGF-1 axis; a meta-analysis confirmed that treating acromegaly with IGF-1 analogues (aiming to reduce the growth hormone/IGF-1 axis activity) reduces the cardiac hypertrophy and improves hemodynamic parameters (13). These findings in adults were also observed in younger patients as well as in animal models (14-16). Recently, we found that nonextremely variations in protein supply with infant formulae resulted in varying kidney growth and function in healthy infants, and this was partly mediated by modulation of the IGF- 1 axis $(3,7)$.

The aim of this study was to assess the effect of different protein intakes during the first year of life on cardiac mass and function at $2 \mathrm{y}$ of age in healthy infants.

\section{RESULTS}

Study Sample

Of the 261 Spanish children remaining in the original European-Childhood Obesity Program randomized trial (trial

${ }^{1}$ Hospital Universitari Sant Joan de Reus, Reus, Spain; ${ }^{2}$ Hospital Universitari de Tarragona Joan XXII, Tarragona, Spain; ${ }^{3}$ Universitat Rovira i Virgili, IISPV, Reus, Spain; ${ }^{4}$ Hauner Children's Hospital, University of Munich Medical Centre, Munich, Germany; ${ }^{5}$ Children's Memorial Health Institute, Warsaw, Poland; ${ }^{6}$ San Paolo Hospital and University of Milan, Milan, Italy. Correspondence: Joaquín Escribano (joaquin.escribano@urv.cat)

Received 7 July 2015; accepted 13 December 2015; advance online publication 16 March 2016. doi:10.1038/pr.2016.30 
number in clinicaltrials.gov NCT00338689), 145 accepted the invitation to attend an additional visit to perform the cardiac assessments at the age of $2 \mathrm{y}$. The assessments were performed between November 2004 and March 2006. The different study groups were composed of 100 formula-fed children of whom 51 and 49 had HP and lower protein (LP) formula, respectively, and 45 were breastfed (BF). Technically acceptable echocardiographic assessments were obtained in 141 children (97\% of the participants); in 4 cases, the triplicate measurements were unsatisfactory and were discarded from the statistical analyses. Triplicate blood pressure measurements were obtained in 110 children (78\% of the participants); 31 children did not fulfill the criteria of technically acceptable readings. At 6 mo of age, a blood sample was drawn in 109 children from the 141 who had had valid echocardiography (Figure 1). All available data from each output were used for the analyses. There were no significant differences in anthropometric measurements from birth to $2 \mathrm{y}$ between infants who had the cardiac assessment and those who did not. Gender distribution as well as anthropometry at birth (weight, length, and head circumference) did not differ between the two formula-fed groups, or between the formula and BF groups.

\section{Effect of Protein Intake on Anthropometry}

As previously observed in the whole EU-Childhood Obesity Program cohort (6), the HP group had higher BMI $z$-scores compared with the LP group $(0.68 \pm 0.77$ vs. $0.22 \pm 0.84$, $P=0.005$ for HP and LP, respectively) at $2 \mathrm{y}$ of age. In addition to the BMI $z$-score, we found significant differences between groups in terms of absolute BMI $(16.7 \pm 1.0$ vs. $16.0 \pm 1.1$, $P=0.006$ for HP and LP, respectively) whereas weight and height did not differ significantly between groups; neither as absolute values (weight: $12.7 \pm 1.3$ vs. $12.3 \pm 1.2, P=0.173$; height: $87.4 \pm 3.2$ vs. $87.8 \pm 2.7, P=0.445$, for HP and LP respectively) nor standardized as $z$-score.

\section{Cardiovascular Parameters}

Results from the echocardiographic assessment showed that cardiac function parameters were modulated by protein intake, whereas cardiac mass did not differ between the feeding groups. LVM was slightly higher in the HP group, but this difference did not reach statistical significance $(29.5 \pm 5.6$ vs. $29.13 \pm 4.3, P=0.69$ for $\mathrm{HP}$ and $\mathrm{LP}$, respectively). Similar results were observed with respect to the indexed left ventricular mass (LVMI) $(42.6 \pm 7.7$ vs. $41.4 \pm 6.0, P=0.400$ for $\mathrm{HP}$ and $\mathrm{LP}$, respectively). However, both ejection fraction (EF) and shortening fraction (SF) were higher among children receiving the HP formula compared with the LP group $(69.1 \pm 5.1$ vs. $66.7 \pm 4.9$ for $\mathrm{EF}$ and $37.7 \pm 4.1$ vs. $35.8 \pm 3.8$ for SF, $P<$ 0.05 for both groups) (Figure 2). Linear regression models using the protein intake $(\mathrm{g} / \mathrm{d})$ from the monthly food diaries were applied to estimate the effect of the formulas on cardiac function. Results showed that each additional $\mathrm{g} / \mathrm{d}$ of protein intake during the first 6 mo of life increased EF and SF at $2 \mathrm{y}$ (Figure 3a). The effect of protein increase was greater during the first month and decreased progressively subsequently; EF increased by $0.52 \%$ for each $\mathrm{g} / \mathrm{d}$ of protein intake increase during the first month of life $(P<0.001), 0.43 \%$ during the second month of life $(P=0.001), 0.31 \%$ during the third $(P<0.01)$ and $0.17 \%$ during the sixth month $(P<0.05)$. The EF and SF values at $2 \mathrm{y}$ were independent of the protein intake from the sixth month onwards. Similarly, protein intake during the first 6 mo (but not subsequently) showed a significant effect on weight and BMI at 2 y (Figure 3b). Multivariate linear regression models adjusted for anthropometric variables were applied to assess whether there was a direct effect of type of formula feeding on EF. Results showed that HP formula feeding was significantly associated with an increase of 2.03 units (95\% CI: 0.07, 4.00) $(P=0.043)$ in $\mathrm{EF}$, despite adjusting for weight $z$-score. Both variables explained up to $11.3 \%$ of EF variability while weight $z$-score alone explained $8.6 \%$. Results of these analyses were similar for SF (data not shown).

Cardiovascular variables were associated with anthropometry at 2 y (Table 1). Cardiac mass and function were significantly correlated with BMI $z$-score, weight $z$-score, length $z$-score, weight gain per month $z$-score, and length gain per month $z$-score. Relationships between cardiac mass and anthropometry values disappear when LVM was indexed as LVMI. In our study, we did not find significant relationships between anthropometry and blood pressure measurements (neither with systolic nor diastolic pressure). We predicted the energy expenditure for each child using the individual's anthropometric data. This parameter was directly correlated with $\mathrm{EF}(r=0.30, P<0.001)$, SF $(r=0.32, P<0.001)$ as well as with LVM $(r=0.43, P<0.001)$. Values of energy expenditure differed between genders $(1,013 \pm 49$ vs. $942 \pm 72 \mathrm{kcal} / \mathrm{d}$ for boys and girls respectively, $P<0.001$ ), but were similar for the overall study groups (HP: $977 \pm 78$; LP: $982 \pm 70$; BF: $966 \pm 67$ $\mathrm{kcal} / \mathrm{d} ; P=0.578)$.

\section{Protein Intake and IGF-1 Axis}

Results of the IGF-1 axis parameters segregated with respect to feeding groups are depicted in Figure 4. HP-fed children showed higher concentrations of free IGF-1, compared with the LP and BF groups and lower concentrations of IGF-1 binding protein 2 compared with LP and BF groups $(P<0.001)$. Total IGF- 1 and IGF- 1 binding protein 3 concentrations were higher in both formula-fed groups compared with BF children.

\section{Relationship Between IGF-1 Axis, Anthropometry, and Cardiovascular Variables}

Total and free IGF-1 showed linear associations with weight $z$-score and BMI $z$-score at 6 mo (total IGF-1: $r=0.300$ and $r=0.255$, $P<0.01$; free IGF-1: $r=0.330, P<0.001$ and $r=0.324, P<0.01$ for weight $z$-score and BMI $z$-score, respectively). Also, free IGF-1 was correlated with weight $z$-score $(r=0.242, P=0.011)$ and BMI $z$-score $(r=0.204, P=0.032)$ at $2 \mathrm{y}$.

No statistically significant relationships were found between cardiac mass at $2 \mathrm{y}$ and the IGF-1 axis parameters at 6 mo. Conversely, cardiac function parameters were associated with IGF-1 binding protein $2(r=-0.199$ and $r=-0.201, P<0.05$ for $\mathrm{EF}$ and SF, respectively) and blood pressure at $2 \mathrm{y}$ was 




Figure 1. Flow chart of study participants. Randomization, follow-up until $2 \mathrm{y}$ of age, and cardiac assessment.

associated with free IGF-1 $(r=0.303, P=0.01$ and $r=0.389, P$ $<0.001$ for sistolic blood pressure and diastolic blood pressure, respectively) measured at 6 mo of age.

Finally, multivariate analyses with linear regression models measuring the influence of feeding type on cardiac function parameters adjusted for weight $z$-score were not altered when IGF-1 was introduced into the model (data not shown).

\section{DISCUSSION}

Nutritional factors influence subsequent development of cardiac function $(17,18)$. Such relationships have only been documented in situations where one or the other was grossly altered, i.e., malnutrition or cardiac pathology. Our study explores, for the first time, the association between neonate nutrition and cardiac function in healthy infants. Our results show that a HP intake in infancy is associated with a higher cardiac systolic function at $2 \mathrm{y}$ of age.

\section{Effect of Protein Intake on Body Structure and Cardiovascular Parameters}

Protein intake during infancy is one of the key nutritional factors affecting obesity risk, and other health consequences later in life $(1,2,6)$. In concordance with the overall EU-Childhood
Obesity Program findings, our results in this (Spanish) subsample support the hypothesis that a HP intake during the first year of life (but within the EU recommended range) produces an increase in the subsequent BMI $z$-score (measured at 2 y), which may confer an increase in subsequent obesity risk (19).

Nutritional factors are able to modulate cardiac function parameters. In animal models, exposure to an excess lipid intake can worsen heart remodeling, leading to contractile dysfunction (20) while, in elderly people, amino acid supplementation improved EF (18). However, the effects of variation in protein intake on cardiac function in healthy neonates have not been studied. Our findings indicate that an increase in protein intake during the first year of life was associated with a subsequent increase in cardiac function parameters measured at $2 \mathrm{y}$ of age. Specifically, the association with cardiac function was found with protein intake during the first month of life, rather than the intake closer to the time of cardiac function measurement. That such an effect of protein intake can be observed $1 \mathrm{y}$ after the end of the intervention, would suggest a programming effect. As expected, we also observed a direct relationship between anthropometric variables and cardiac function parameters. Therefore, one could hypothesize that the effect of protein intake on cardiac function could be exerted 
indirectly through an anthropometric modulation of body size. This hypothesis would be in line with the proposed mechanism by which an increase in total body surface implies an increase in the cardiac output to fulfill the organism's higher $\mathrm{O}_{2}$ requirements (21). Higher body weight implies higher energy expenditure and energy expenditure is tightly related to cardiac output. Accordingly, as in our study, protein intake would be associated to weight gain $(6,22,23)$ and, in which, weight gain as well as protein intake would be related to cardiac function. On the other hand, anthropometric measures were associated with energy expenditure and cardiac function. This suggests that an increase in body surface would be accompanied by a rise in cardiac output which, in turn, depends directly on the EF. Despite the evidence of an indirect effect of protein intake on cardiac function parameters via body size modulation, a direct effect on the cardiac system cannot be completely rejected since we had found that the type of formula was significantly associated with EF, even in the multiple regression models when adjusted for body size.

Cardiac mass has been shown to vary with dietary protein intake in pathologic situations such as protein-related malnutrition in humans (24) or overfeeding in rats (12). In our study, the effect of early protein intake on the body-growth parameters was accompanied by the expected association of these parameters with the $\operatorname{LVM}(21,25)$. One of our objectives was to determine whether the protein supplied by milk formula
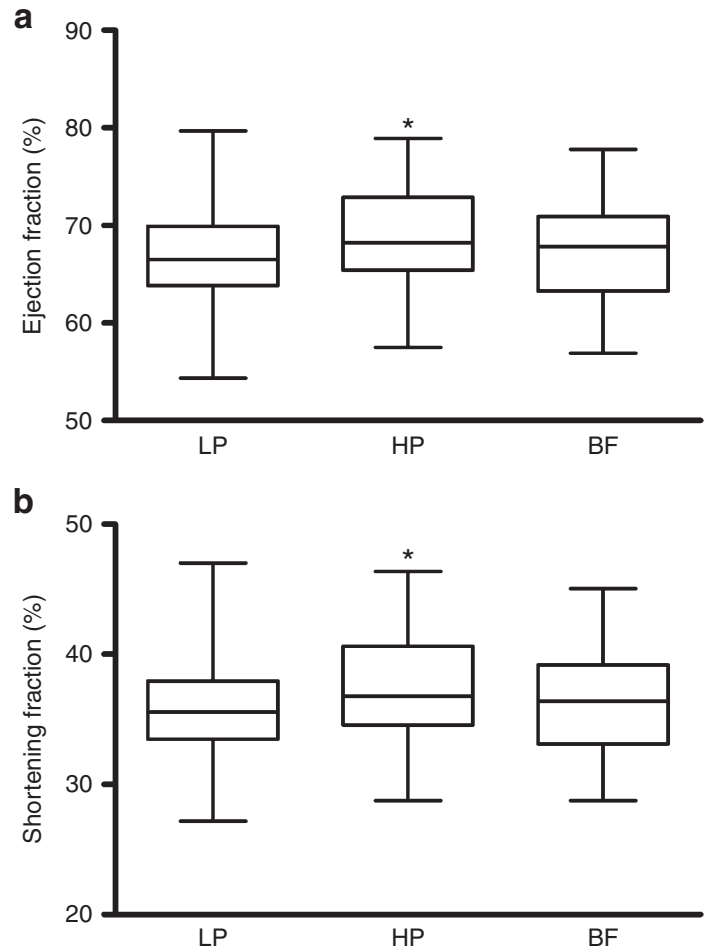

Figure 2. Cardiac function. Cardiac function parameters (EF in a and SF in b) segregated by feeding type. ${ }^{*} P<0.05$ vs. LP. EF, ejection fraction; $\mathrm{LP}$, lower protein; SF, shortening fraction.
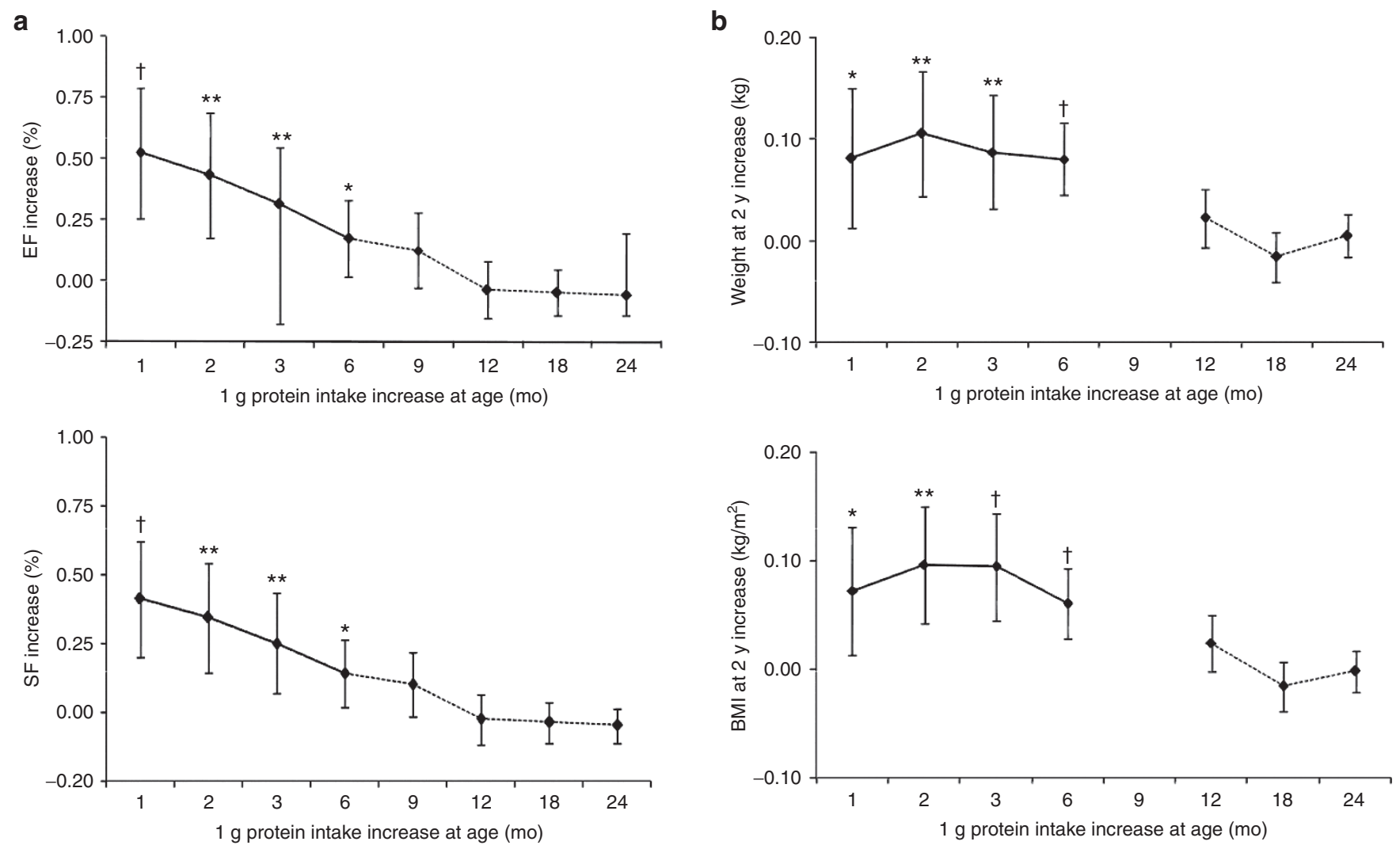

Figure 3. Protein intake effects. Effect of increase $1 \mathrm{~g} / \mathrm{d}$ in protein intake on: (a) EF and SF; (b) weight and BMI. ${ }^{*} P<0.05,{ }^{* *} P<0.01,{ }^{\dagger} P<0.001$. EF, ejection fraction; $\mathrm{SF}$, shortening fraction. 


\section{Articles $\mid$ Collell et al.}

during fast-growth periods could induce changes in cardiac structure, as evidence by changes in cardiac mass measured by echocardiography. We observed a slight increase in the LVM among those children receiving the HP formula during the first year of life, but these differences did not reach statistical significance. The lack of significance could be because of the limited sample size precluding the identification of subtle changes. The short time span over which the study was conducted may have contributed, as well. Our results suggest that an effect of protein intake on cardiac mass may be produced via modulation of body size and structure. The rationale for this conclusion was the direct correlation between anthropometric variables and LVM, but not with LVMI, as indexed by length.

A possible protective effect of breastfeeding on later development of hypertension, secondary to a LP intake with human

Table 1. Correlation coefficients between anthropometric variables and cardiac parameters

\begin{tabular}{llll}
\hline Anthropometric variable & EF (\%) & SF (\%) & LVM (g) \\
\hline Weight for age at 24 mo ( score) & $0.305^{\dagger}$ & $0.323^{\dagger}$ & $0.354^{\dagger}$ \\
Length for age at 24 mo (z score) & $0.221^{* *}$ & $0.241^{*}$ & $0.364^{\dagger}$ \\
BMI for age at 24 mo (z score) & $0.231^{* *}$ & $0.238^{* *}$ & $0.174^{*}$ \\
Weight gain per month (kg/mo) & $0.346^{\dagger}$ & $0.363^{\dagger}$ & $0.402^{\dagger}$ \\
Length gain per month (cm/mo) & $0.259^{* *}$ & $0.277^{* *}$ & $0.361^{\dagger}$
\end{tabular}

$E F$, ejection fraction; $L V M$, left ventricular mass; $S F$, shortening fraction.

${ }^{+} P<0.001,{ }^{* *} P<0.01,{ }^{*} P<0.05$

a



C

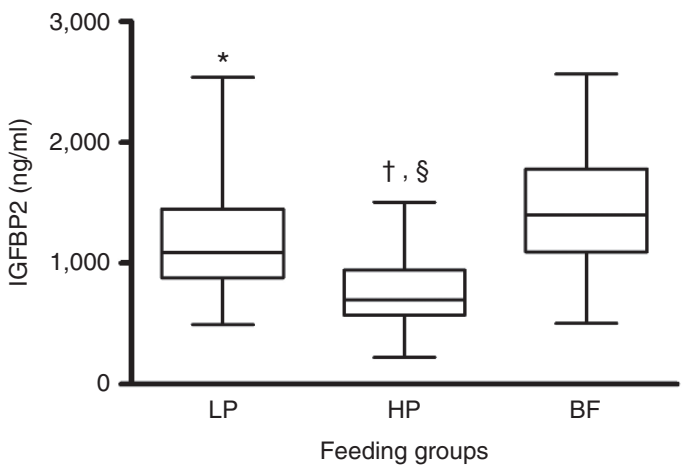

milk, has been proposed (26). In our study, we did not find significant differences in blood pressure measurements between the feeding groups, which may be influenced by the young age of the participants at the time of the cardiac study.

\section{Role of the IGF-1 Axis}

Protein intake has been directly associated with IGF-1 secretion $(27,28)$. This mechanism is partly responsible for the protein-induced increase in anthropometric parameters, as well as in some internal organs such as the kidney in healthy children $(7,29)$. Protein intake induces IGF-1 secretion which, in turn, induces an increase in weight through its anabolic and metabolic effects in most cell lines $(30,31)$. As cardiac growth and remodeling are also influenced by the IGF-1 in a physiologic as well as pathologic manner (32-34), we sought relationships between these parameters. Our findings show that the HP group presented higher concentrations of free IGF-1 as well as lower concentrations of IGF-1 binding protein 2 (transport protein that inhibits the IGF-1 action) compared with LP and BF groups. IGF-1 concentrations were associated with weight and BMI at 6 mo, while free IGF- 1 also correlated with these parameters at the age of $2 \mathrm{y}$. However, we did not find any relationship between IGF-1 axis parameters (neither total nor free IGF-1, nor its transport proteins) with cardiac mass.

The protein-induced increase in weight and size of certain organs produces a metabolic overload that implies an increase in cardiac output. Our results show a direct influence of protein intake on cardiac function parameters, suggesting a possible

b

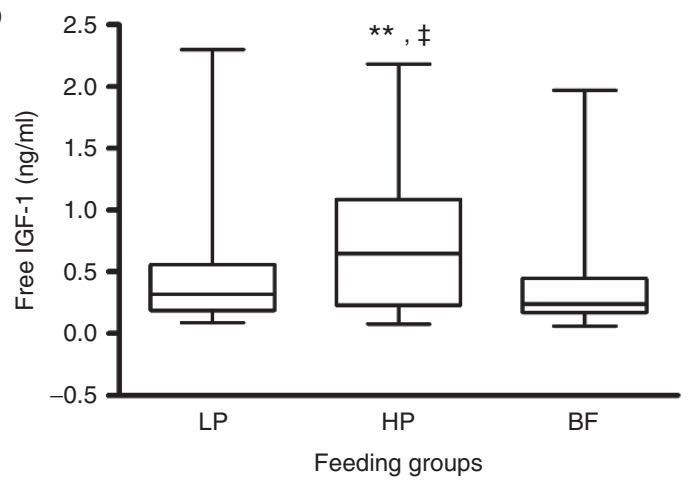

d



Figure 4. IGF-1 axis parameters segregated by feeding type. (a) Total IGF-1, (b) free IGF-1, (c) IGFBP2, and (d) IGFBP3. ${ }^{*} P<0.05$, ${ }^{* *} P<0.01,{ }^{\dagger} P<0.001$ vs. $\mathrm{BF} ;{ }^{\ddagger} P<0.05,{ }^{\lessgtr} P<0.001$ vs. LP. BF, breastfed; IGF-1, insulin-like growth factor 1; IGFBP2, IGF-1 binding protein 2; IGFBP3, IGF-1 binding protein 3; LP, lower protein. 
modulation towards an increase in IGF-1 and organ development resulting from the early protein intake. These changes could suggest an early programming effect, with changes in function resulting in subsequent structural changes. However, since the effect of the type of formula on cardiac function parameters remains significant even following adjustment for IGF-1 (total as well as free), our results are unable to distinguish whether an independent IGF-1 axis mechanism would still play a role.

\section{Protein-Induced Metabolic Consequences on the Cardiovascular System}

Nutrient intakes during rapid-growth phases are able to affect body structure and function. The effect of protein supply during gestation and early infancy is one of the main nutritional factors that could modulate later risk of obesity and hypertension as well as kidney size and function $(4,35)$. Our results suggest that this mechanism is also able to influence the cardiac system through an indirect mechanism via overall growth of the body, accompanied by an increased metabolic expenditure (i.e., energy expenditure) and a consequent increased cardiac workload. Possibly, cardiac workload or whatever involves increased $\mathrm{O}_{2}$ requirements in children with greater body surface can determine the long-term increase in cardiac mass, as evidenced in obese individuals (36). However, we are unable to explore this hypothesis in the 2-y olds because of the short time course of the study encompassing a short developmental period and the low prevalence of obese infants observed at this age. We would not expect this slight change in cardiac mass to exert health effects on healthy children. However, long-term effects if overweight persists would require further investigation. Consequently, if health consequences could be predicted by the formula diets administered to the infants, then it would be important to revise infant formula regulations. Figure 5 presents a rationale to explain our findings, particularly the main steps involved in the early-phase period.

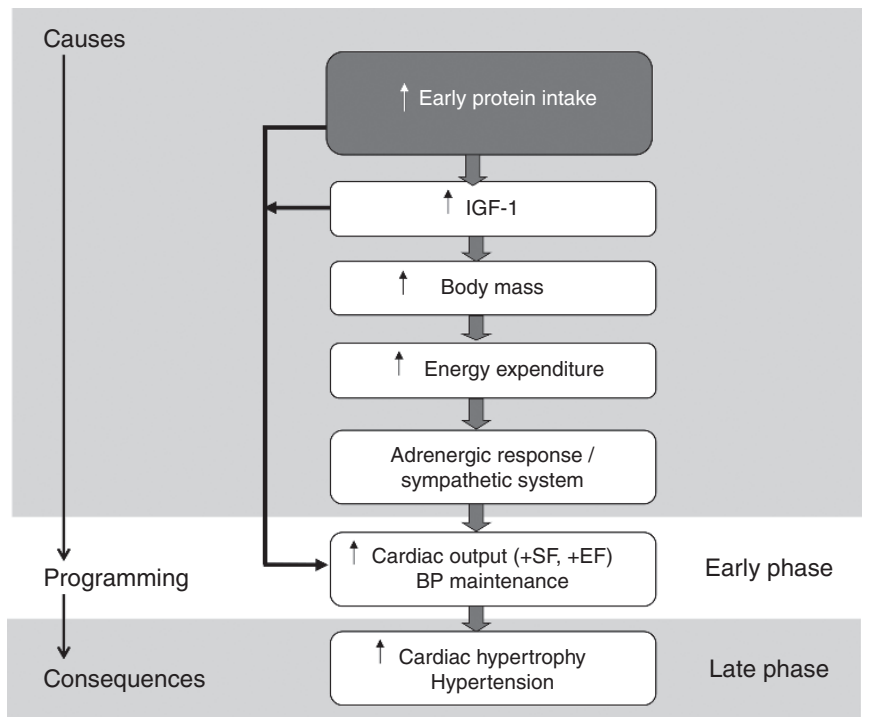

Figure 5. Rationale proposal. Possible protein-induced metabolic "programming pathways" influencing the cardiovascular system structure and function.
The increase in early protein intake could induce an increase in IGF-1 that produced an increase in body mass with the corresponding raise in energy expenditure. A posterior adrenergic response in the sympathetic system could mediate an increase in the cardiac output, observed as increases in cardiac function parameters. These mechanisms have potential long-term effects. However, we are unable to extrapolate our findings to later-stage developments.

A potential limitation of this study is the exclusion of blood pressure measurements from 32 infants (23\% of the participants) due to insufficient or unreliable measurements/readings. However, there were no significant differences in the excluded infants with respect to feeding-group distributions. A further limitation is that the IGF-1 axis determinations were performed in a single blood sample. This was unavoidable since repeated blood sampling in infants is difficult to achieve. Another limitation is sample size. The study sample did not provide sufficient statistical power to detect slight differences in cardiac mass between the feeding groups. Despite these limitations, the study provides new data obtained in a group of healthy infants that had been randomized at birth to receive infant formula diets. Confidence in the measurements was assured by high-standard anthropometric measurement protocols and echocardiographic assessment by a single expert clinical cardiologist who was blinded with respect to the dietary provenance of the infants.

In summary, our study demonstrated that a moderate increase in protein intake during the first year of life is associated not only with higher BMI but also higher cardiac function parameters at $2 \mathrm{y}$ of age. However, we did not find changes in cardiac mass at this early stage of the child's development. The IGF-1 axis may partly mediate these effects by an indirect pathway that induces changes in the body size as well as on energy expenditure. Further investigation is warranted to elucidate the clinical applications of this nutritional programming effect in infancy.

\section{METHODS}

\section{Study Design and Population Sample}

The study was performed in the Spanish subsample of infants from the EU Childhood Obesity Program trial. This study is an ongoing European collaborative randomized controlled trial in five European countries (Belgium, Germany, Italy, Poland, and Spain) investigating the long-term consequences of different protein intakes during the first year of life (6). The double-blinded randomized, clinical trial [NTC00338689] comparing two groups of infants fed, during the first year of life, either HP or LP content formulas; both within the recommended range for desired growth and development. The primary aim of the clinical trial was to evaluate the influence of this variation in protein intake on early growth and subsequent obesity. A nonrandomized group of infants exclusively BF during the first 3 mo of life was followed up as a reference group.

Dietary intake and growth parameters were assessed periodically during the first 2 y of life $(6,37)$. A blood sample was taken at 6 mo of age. Echocardiography and blood pressure measurements were performed at the age of $2 \mathrm{y}$.

Infant formulas had a percentage of the energy content provided by proteins of 7.1 vs. $11.7 \%(1.25 \mathrm{~g} / 100 \mathrm{ml}$ vs. $2.05 \mathrm{~g} / 100 \mathrm{ml}$ for LP and HP, respectively), and follow-on formulas provided 8.8 vs. $17.6 \%$ of energy content $(1.6 \mathrm{~g} / 100 \mathrm{ml}$ vs. $3.2 \mathrm{~g} / 100 \mathrm{ml}$ for LP and HP, respectively). Equal energy content in both study formulas was achieved 
by increasing the fat content in the LP formula. Carbohydrates and other nutrients were not significantly different. Further details on the study formulas and protocols have been published elsewhere (6). The composition of all study formulas complied with the 1991 European Union Directive on Infant and Follow-on Formulae (38) in place at the time of the study. The protein contents represented approximately the lowest and highest levels of the range recommended in this directive.

\section{ASSESSMENTS}

\section{Anthropometry}

Weight was measured using a Seca 702 scale with a precision of $\pm 0.05 \mathrm{~kg}$ (Seca, Hamburg, Germany). Recumbent length was measured at birth using Seca 232 (Seca) and a PED LB 35-107 $\mathrm{X}$ (Ellard Instrumentation, Monreo, WA); both with a precision of $\pm 1 \mathrm{~mm}$ at the age of $24 \mathrm{mo}$. Body mass index:

$\operatorname{BMI}\left(\mathrm{kg} / \mathrm{m}^{2}\right)=\frac{\text { weight }}{\text { length }\left(\mathrm{m}^{2}\right)}$ and total body surface :

$\operatorname{BSA}\left(\mathrm{m}^{2}\right)=\sqrt{\frac{\text { weight }(\mathrm{kg}) \times \text { length }(\mathrm{cm})}{3,600}}$

were calculated (39). Weight-gain per month and length-gain per month from birth to 2 y were calculated. All anthropometric variables were transformed into $z$-scores, according to the World Health Organization Standards (40) using the WHO Anthro for personal computers software (World Health Organization, Geneva, Switzerland).

\section{Blood Analyses}

Serum parameters analyzed at 6 mo of age were: total IGF-1 $(\mathrm{ng} / \mathrm{mL})$, free IGF-1 $(\mathrm{ng} / \mathrm{mL})$, IGF-1 binding protein $2(\mathrm{ng} /$ $\mathrm{mL}$ ), and IGF-1 binding protein $3(\mathrm{ng} / \mathrm{mL})$. Serum samples were frozen at $-70{ }^{\circ} \mathrm{C}$ until analyzed in a centralized laboratory in Warsaw (Children's Memorial Health Institute, Warsaw, Poland) (41). The IGF-1 axis analyses were performed by radioimmunoassay using commercial kits according to the manufacturer's instructions (Diagnostic Systems Laboratories, Webster, TX).

\section{Cardiac Assessment}

Transthoracic Doppler echocardiography was performed by a single pediatric cardiologist (R.C.) to assess cardiac mass and function. The device used was VIVID 4 with a $5-\mathrm{MHz}$ transductor allowing bidimensional M-mode evaluation (General Electrics, New York, NY). The following parameters were measured in triplicate: interventricular septum thickness in systole, interventricular septum thickness in diastole, left ventricular posterior wall in systole, left ventricular posterior wall in diastole, left ventricular diastolic diameter, left ventricular systolic diameter. Calculated variables were: LVM (g), LVMI as LVM (g)/length $(\mathrm{m})^{2.7}, \mathrm{EF}(\%)$ and SF (\%). LVM was calculated according to the recommendations of the American Society of Echocardiography as modified by Devereux as follows:

\section{$\mathrm{LVM}=\left\{1.04\left[(\mathrm{dIVS}+\mathrm{dLVD}+\mathrm{dLVPW})^{3}-\mathrm{dLVD}^{3}\right]\right\}+0.6$}

where dIVS is the interventricular septum thickness in diastole, dLVD is the left ventricular diastolic diameter, and dLVPW is the left ventricular posterior wall in diastole. LVMI was calculated as recommended by de Simone $(25,42)$ as: $\mathrm{LVMI}=\mathrm{LVM} /$ length ${ }^{2.7}$.

Cardiac function was evaluated using M-mode echocardiographic examination to determine left ventricular systolic function. EF and SF were calculated digitally using the Teicholz method (43).

All echocardiographic measurements were performed according to the recommendations of the American Society of Echocardiography (43).

At the 2-y visit, blood pressure measurements were performed in triplicate using the oscillometric monitor Dinamap Pro 300 (precision: $\pm 8 \mathrm{mmHg}$ ). The mean value was used in the statistical analyses. The appropriate cuff was applied with the subject in sitting position on the mother's lap. Not being able to obtain three valid blood pressure measurements was a criterion to remove this variable from the statistical analyses.

\section{Total Energy Expenditure Assessment}

Total energy expenditure as $\mathrm{kcal} / \mathrm{d}$ was calculated using the Schofield equations (44) below for basal metabolic rate:

$\mathrm{BMR}=[0.167 \times$ weight $(\mathrm{kg})+1,517.4 \times$ length $(\mathrm{m})-617.6]$

or

$$
\text { BMR }=[16.25 \times \text { weight }(\mathrm{kg})+1,023.2 \times \text { length }(\mathrm{m})-413.5]
$$

for boys and girls, respectively. The total energy expenditure was then calculated using the physical activity levels as described by Butte et al (45) at 2 y as:

Total energy expenditure $(\mathrm{kcal} / \mathrm{d})=\mathrm{BMR}(\mathrm{kcal}) \times 1.4$.

\section{Data Analysis}

Data management and statistical analyses were carried out with the SPSS Statistics software package version 20.0 (IBM, Armonk, $\mathrm{NY}$ ). Descriptive results are presented as frequencies for categorical variables and as mean $( \pm S D)$ for continuous variables. Frequency distributions between feeding types were compared with the $\chi^{2}$ test. Anthropometry, blood variables as well as cardiac mass and function between dietary formulas were compared with Student's $t$-test or Mann-Whitney $U$-test (for normally and non-normally distributed variables, respectively) or by ANOVA analysis and Bonferroni post hoc correction for multiple testing when BF infants were also included in the analyses. Linear associations between cardiac variables and the other continuous variables were analyzed by Pearson or Spearman correlation coefficients, as appropriate. Linear regression models were applied to evaluate the effect of feeding type on cardiac mass and function. Adjustment was performed using anthropometric variables. Also, linear regression models were applied to determine the effect of daily protein intake during first mo of life on cardiac variables, and on body weight or BMI. Statistical significance was accepted at the level of $P<0.05$. 


\section{Ethical Considerations}

The local Ethical Committees approved the study. All study procedures conformed to the Helsinki II declaration. Written informed parental consent was obtained for each infant. Data were codified to ensure anonymity.

\section{ACKNOWLEDGMENTS}

We are very grateful to the families took part enthusiastically in the Childhood Obesity Project. Investigators and their institutions participated in the European Childhood Obesity Project: Beyer J., Fritsch M., Haile G., Handel U., Hannibal I., Kreichauf S., Pawellek I., Schiess S., Verwied-Jorky S., von Kries R., Weber M. (Children's University Hospital, University of Munich Medical Centre, Munich, Germany), Dobrzańska A., Gruszfeld D., Wierzbicka A., Socha P., Stolarczyk A., Socha J. (Children's Memorial Health Institute, Warsaw, Poland), Carlier C., Dain E., Goyens P., Van Hees J.N., Hoyos J., Langhendries J.P., Martin F., Poncelet P., Xhonneux A., (ULB Bruxelles and CHC St Vincent Liege), Perrin, E. (Danone Research Centre for Specialised Nutrition, Schiphol, The Netherlands), Agostoni C., Giovannini M., Re Dionigi A., Riva E., Scaglioni S., Vecchi F. (University of Milan), Mendez-Riera G., Zaragoza-Jordana M., Gispert-Llaurado M., Rubio-Torrents C. (Universitat Rovira I Virgili, Spain).

\section{STATEMENT OF FINANCIAL SUPPORT}

The studies reported herein have been carried out with partial financial support from the European Union, within the 5th Framework Programme (research grant number QLRT-2001-00389 and number QLK1CT-2002-30582), the 6th Framework Programme (contract number 007036), and the 7th Framework Programme (FP7/2008-2013) (under grant agreement number 212652) (NUTRIMENTHE Project "The Effect of Diet on the Mental Performance of Children" and (FP7/2007-2013), under the grant agreement number 289346 (project EarlyNutrition)). This manuscript does not necessarily reflect the views of the Commission and in no way anticipates the future policy in this area.

Investigators and their institutions in the European Childhood Obesity Project Group are included in the Acknowledgments.

Disclosure: The authors affirm that there is no potential conflict of interest and that there were no financial ties to products in the study.

\section{REFERENCES}

1. Lucas A. Programming by early nutrition: an experimental approach. J Nutr 1998;128:Suppl 2:401S-6S.

2. Koletzko B. Early nutrition and its later consequences: new opportunities. Adv Exp Med Biol 2005;569:1-12.

3. Escribano J, Luque V, Ferre $\mathrm{N}$, et al. Increased protein intake augments kidney volume and function in healthy infants. Kidney Int 2011;79: 783-90.

4. Metges CC. Longterm effects of pre- and postnatal exposure to low and high dietary protein levels. Evidence from epidemiological studies and controlled animal experiments. Adv Exp Med Biol 2005;569:64-8.

5. Murray BM, Campos SP, Schoenl M, MacGillivray MH. Effect of dietary protein intake on renal growth: possible role of insulin-like growth factorI. J Lab Clin Med 1993;122:677-85.

6. Koletzko B, von Kries R, Closa R, et al.; European Childhood Obesity Trial Study Group. Lower protein in infant formula is associated with lower weight up to age 2 y: a randomized clinical trial. Am J Clin Nutr 2009;89:1836-45.

7. Luque V, Escribano J, Grote V, et al.; European Childhood Obesity Project. Does insulin-like growth factor-1 mediate protein-induced kidney growth in infants? A secondary analysis from a randomized controlled trial. Pediatr Res 2013;74:223-9.

8. Elmes MJ, Gardner DS, Langley-Evans SC. Fetal exposure to a maternal low-protein diet is associated with altered left ventricular pressure response to ischaemia-reperfusion injury. Br J Nutr 2007;98:93-100.

9. Kothari SS, Patel TM, Shetalwad AN, Patel TK. Left ventricular mass and function in children with severe protein energy malnutrition. Int J Cardiol 1992;35:19-25.

10. Ocal B, Unal S, Zorlu P, Tezic HT, Oğuz D. Echocardiographic evaluation of cardiac functions and left ventricular mass in children with malnutrition. J Paediatr Child Health 2001;37:14-7.
11. Faddan NH, Sayh KI, Shams H, Badrawy H. Myocardial dysfunction in malnourished children. Ann Pediatr Cardiol 2010;3:113-8.

12. Moreira AS, Teixeira Teixeira M, da Silveira Osso F, et al. Left ventricular hypertrophy induced by overnutrition early in life. Nutr Metab Cardiovasc Dis 2009;19:805-10.

13. Maison P, Tropeano AI, Macquin-Mavier I, Giustina A, Chanson P. Impact of somatostatin analogs on the heart in acromegaly: a metaanalysis. J Clin Endocrinol Metab 2007;92:1743-7.

14. Minniti G, Jaffrain-Rea ML, Moroni C, et al. Echocardiographic evidence for a direct effect of GH/IGF-I hypersecretion on cardiac mass and function in young acromegalics. Clin Endocrinol (Oxf) 1998;49:101-6.

15. Heineke J, Molkentin JD. Regulation of cardiac hypertrophy by intracellular signalling pathways. Nat Rev Mol Cell Biol 2006;7:589-600.

16. Cittadini A, Strömer H, Katz SE, et al. Differential cardiac effects of growth hormone and insulin-like growth factor- 1 in the rat. A combined in vivo and in vitro evaluation. Circulation 1996;93:800-9.

17. Zhou YT, Grayburn P, Karim A, et al. Lipotoxic heart disease in obese rats: implications for human obesity. Proc Natl Acad Sci USA 2000;97: $1784-9$.

18. Scognamiglio R, Piccolotto R, Negut C, Tiengo A, Avogaro A. Oral amino acids in elderly subjects: effect on myocardial function and walking capacity. Gerontology 2005;51:302-8.

19. Weber M, Grote V, Closa-Monasterolo R, et al.; European Childhood Obesity Trial Study Group. Lower protein content in infant formula reduces BMI and obesity risk at school age: follow-up of a randomized trial. Am J Clin Nutr 2014;99:1041-51.

20. Chess DJ, Lei B, Hoit BD, Azimzadeh AM, Stanley WC. Effects of a high saturated fat diet on cardiac hypertrophy and dysfunction in response to pressure overload. J Card Fail 2008;14:82-8.

21. Iacobellis G, Ribaudo MC, Zappaterreno A, Iannucci CV, Di Mario U, Leonetti F. Adapted changes in left ventricular structure and function in severe uncomplicated obesity. Obes Res 2004;12:1616-21.

22. Escribano J, Luque V, Ferre N, et al.; European Childhood Obesity Trial Study Group. Effect of protein intake and weight gain velocity on body fat mass at 6 months of age: the EU Childhood Obesity Programme. Int J Obes (Lond) 2012;36:548-53.

23. Stettler N, Zemel BS, Kumanyika S, Stallings VA. Infant weight gain and childhood overweight status in a multicenter, cohort study. Pediatrics 2002;109:194-9.

24. Webb JG, Kiess MC, Chan-Yan CC. Malnutrition and the heart. CMAJ 1986;135:753-8.

25. de Simone G, Daniels SR, Devereux RB, et al. Left ventricular mass and body size in normotensive children and adults: assessment of allometric relations and impact of overweight. J Am Coll Cardiol 1992;20:1251-60.

26. Martin RM, Ness AR, Gunnell D, Emmett P, Davey Smith G; ALSPAC Study Team. Does breast-feeding in infancy lower blood pressure in childhood? The Avon Longitudinal Study of Parents and Children (ALSPAC). Circulation 2004;109:1259-66.

27. Hoppe C, Udam TR, Lauritzen L, Mølgaard C, Juul A, Michaelsen KF. Animal protein intake, serum insulin-like growth factor I, and growth in healthy 2.5-y-old Danish children. Am J Clin Nutr 2004;80:447-52.

28. Axelsson I. Effects of high protein intakes. Nestle Nutr Workshop Ser Pediatr Progr 2006;58:121-9; discussion 129-31.

29. Escribano J, Luque V, Ferre N, et al. Increased protein intake augments kidney volume and function in healthy infants. Kidney Int 2011;79:783-90.

30. Axelsson IE, Ivarsson SA, Räihä NC. Protein intake in early infancy: effects on plasma amino acid concentrations, insulin metabolism, and growth. Pediatr Res 1989;26:614-7.

31. Karlberg J, Jalil F, Lam B, Low L, Yeung CY. Linear growth retardation in relation to the three phases of growth. Eur J Clin Nutr 1994;48:Suppl 1:S25-43; discussion S43-4.

32. McMullen JR. Role of insulin-like growth factor 1 and phosphoinositide 3-kinase in a setting of heart disease. Clin Exp Pharmacol Physiol 2008;35:349-54.

33. Petretta M, Colao A, Sardu C, et al. NT-proBNP, IGF-I and survival in patients with chronic heart failure. Growth Horm IGF Res 2007;17:288-96. 


\section{Articles | collelle tal.}

34. Colao A. The GH-IGF-I axis and the cardiovascular system: clinical implications. Clin Endocrinol (Oxf) 2008;69:347-58.

35. Langley-Evans SC. Nutritional programming of disease: unravelling the mechanism. J Anat 2009;215:36-51.

36. Lauer MS, Anderson KM, Kannel WB, Levy D. The impact of obesity on left ventricular mass and geometry. The Framingham Heart Study. JAMA 1991;266:231-6.

37. Schiess S, Grote V, Scaglioni S, et al.; European Childhood Obesity Project. Introduction of complementary feeding in 5 European countries. J Pediatr Gastroenterol Nutr 2010;50:92-8.

38. Comission E. Commission Directive 91/321/EEC of 14 May 1991 on infant and follow-on formulae. Off J Eur Comm 1991;35-49.

39. Mosteller RD. Simplified calculation of body-surface area. N Engl J Med 1987;317:1098.

40. Group WHOMGRS. WHO Child Growth Standards based on length/ height, weight and age. Acta Paediatr Suppl 2006;450:S76-85.
41. Socha P, Grote V, Gruszfeld D, et al.; European Childhood Obesity Trial Study Group. Milk protein intake, the metabolic-endocrine response, and growth in infancy: data from a randomized clinical trial. Am J Clin Nutr 2011;94:Suppl 6:1776S-84S.

42. Rosa EC, Moyses VA, Sesso RC, et al. Left ventricular hypertrophy evaluation in obese hypertensive patients: effect of left ventricular mass index criteria. Arq Bras Cardiol 2002;78:341-51.

43. Sahn DJ, DeMaria A, Kisslo J, Weyman A. Recommendations regarding quantitation in M-mode echocardiography: results of a survey of echocardiographic measurements. Circulation 1978;58: 1072-83.

44. Schofield WN. Predicting basal metabolic rate, new standards and review of previous work. Hum Nutr Clin Nutr 1985;39:Suppl 1:5-41.

45. Butte NF, Wong WW, Hopkinson JM, Heinz CJ, Mehta NR, Smith EO. Energy requirements derived from total energy expenditure and energy deposition during the first $2 \mathrm{y}$ of life. Am J Clin Nutr 2000;72:1558-69. 